\title{
On the Impacts of Pressured vs. Unpressured On- line Task Planning on EFL Students' Oral Production in Classroom and Testing Contexts
}

\author{
Vahid Panahzadeh a * (D), Bita Asadi b ${ }^{\circ}$ (iD) \\ a Allameh Tabataba'i University, Tehran, Iran \\ ${ }^{b}$ Department of English, Malard Branch, Islamic Azad University, Malard, Iran
}

Received 16 September 2018 | Received in revised form 31 December 2018 | Accepted 28 April 2019

\begin{abstract}
APA Citation:
Panahzadeh, V. \& Asadi, B. (2019). On the impacts of pressured vs. unpressured on-line task planning on EFL students' oral production in classroom and testing contexts. Eurasian Journal of Applied Linguistics, 5(3), 341-352. Doi: 10.32601/ejal.651267
\end{abstract}

\begin{abstract}
The literature on task planning abounds with studies in laboratory or classroom contexts; however, the contribution of task planning to the testing context has remained a largely uncharted area of enquiry. The current study is primarily focused on exploring the impacts of pressured vs. unpressured on-line task planning conditions on EFL students' oral production in classroom and testing contexts. The participants of the study comprised a total of 14 Iranian intermediate adult female EFL students from a private language institute in Tehran. Two parallel task cards- part 2 of IELTS Speaking Test- were given to students with and without any time pressure for task completion in the two different contexts in fulfilment of the requirement for promotion for the next instructional period. All performances were measured through fluency and coherence (FC), lexical resource (LR), and grammatical range and accuracy (GRA) indices. To compare the impacts of pressured and unpressured on-line task planning in the classroom and testing contexts, paired samples t-tests were conducted in SPSS. It was found that the removal of time pressure on students' task performance significantly impacted on their GRA in the classroom context. Regarding the testing context, it was found that, as with the classroom context, pressured on-line task planning led to higher FC compared to other indices. Also, it was found that unpressured on-line task planning had a statistically significant impact on students' GRA. Moreover, the authors observed that a trade-off effect exists between students' GRA and FC and their LR in the testing context; in other words, the more the students were stressed out to accomplish the test task and to produce correct sentences to get higher scores, the less they took risks to try extensive vocabulary and the lower their LR became.
\end{abstract}

(C) 2019 EJAL \& the Authors. Published by Eurasian Journal of Applied Linguistics (EJAL). This is an open-access article distributed under the terms and conditions of the Creative Commons Attribution license (CC BY-NC-ND) (http://creativecommons.org/licenses/by-nc-nd/4.0/).

Keywords: On-line task planning; testing context; oral performance; lexical resource; grammatical range and accuracy

\footnotetext{
* Corresponding author. Tel.: +98-9358590700

E-mail address: Panahzade.vahid@gmail.com

† uniqe bita2002@yahoo.com
} 


\section{Introduction}

Second language (L2) researchers have recently provided unqualified support for task-based language teaching (TBLT) (e.g., Ahmadian \& García Mayo, 2017; Long, 2014; Skehan, 2011). As "a new orthodoxy" within current language teaching pedagogy (Littlewood, 2004, p. 319), TBLT has primarily focused on fostering learners' language development through provision of authentic language input and opportunity for meaningful language use (Mackey \& Silver, 2005). Task-based pedagogy is of the potential to induce interaction between students which may, in turn, facilitate ultimate attainment through providing opportunities for processing of input, negotiation of meaning, language production, attention, feedback, and noticing (Gass, 2003; Keyvanfar \& Modarresi, 2009). In effect, Foster and Skehan (1999) suggested conceiving of tasks as "providing opportunities to achieve particular instructional goals" (p. 217); that is to say, tasks may prove highly advantageous when they target a particular pedagogic outcome.

A vast body of research has been undertaken into various design features as well as implementation procedures of tasks, and their potential impacts on second language (L2) students' performance criteria such as complexity, accuracy, and fluency (CAF) (Ellis, 2005; Skehan, 1998). Task planning, being one of such implementation procedures, has been widely attended to and shown to result in relatively consistent effects on L2 production. It has been operationalized in terms of pre-task planning and within-task planning (i.e., on-line task planning), with the former occurring before the task is performed and the latter occurring during task performance (Ellis, 2005). Different sub-categories of pre-task planning, namely rehearsal and strategic planning, have been proposed in the literature. Rehearsal refers to the presentation of task materials to the students in order to be practiced prior to main performance; strategic planning, not unlike rehearsal, refers to the presentation of task content to the students in order to brainstorm the content they will need to perform the task (Ellis, 2005). It is noteworthy that in the pre-task planning "the learners have access to the actual task materials" (Ellis, 2005, p. 3).

On-line task planning, on the other hand, refers to "the moment-by-moment planning during the task performance" (Yuan \& Ellis, 2003, p. 4). It can be either pressured or unpressured, which are simply distinguished in terms of the amount time students have for the planning of their task performance on-line; that is to say, while a time limit is set on students' task performance in pressured task planning, there is no such a limit for the task performance in unpressured task planning which paves the way for planned language use (Ellis, 2009; Markee \& Kunitz, 2013; Mystkowska-Wiertelak, 2011). Yuan and Ellis (2003) underscored there major advantages of on-line task planning over pre-task planning, namely (a) helping students to thoroughly search their linguistic resources to encode the content; (b) assisting students with controlling their output prior to real-time production; and (c) encouraging students to review their output after its production. 
Virtually all task planning studies have drawn on information processing perspective positing that humans have limited cognitive capacity (Skehan, 1998; VanPatten, 1990, 2002). Skehan (1998) contended that students' deficient L2 proficiency may exert mounting pressure on their attention; as a result, they are faced with the dilemma of opting for only one aspect of performance (e.g., accuracy or fluency). On the basis of this perspective, students cannot easily attend to two or more mental activities at the same time; consequently, attention may be predominantly devoted to only one aspect of language (e.g., meaning or form) (VanPatten, 2002). According to Ellis (2005), providing students with planning time "mitigates the limitations of their working memory by allowing learners the 'cognitive window' needed to attend to form while they are primarily concerned with message conveyance" (p. 10).

The notion of oral task planning has been conceptualized in reference to Levelt's (1989) first language (L1) production model in the literature. Levelt's model, as one of the universally recognized models in L2 production, consists of three overlapping processing stages of conceptualization (i.e., generating the conceptual content of speech), formulation (i.e., drawing upon mental lexicon to encode the content), and articulation (i.e., giving a phonological shape and articulating internally formulated content). Also, another important and relevant component of speech production is monitoring through which the output is controlled, both before and after speech production, by constantly reviewing both internal and external speech (Levelt, Roelofs, \& Meyer, 1999).

The last two decades have witnessed a considerable amount of research on the impacts of different task planning conditions on L2 production- both oral and written. As for students' oral production, the majority of these studies have made use of complexity, accuracy, and fluency (CAF) indices to measure students' performance. It has generally been demonstrated that pre-task planning has positive impacts on students' oral production fluency and complexity (e.g., Ellis, 2009; Saeedi, 2013); however, regarding students' oral production accuracy, the results have been largely inconclusive with some showing positive impacts (e.g., Tavakoli \& Skehan, 2005) and some showing no significant impacts (e.g., Yuan \& Ellis, 2003) of pre-task planning on students' oral production.

As for on-line planning, the positive impacts of planning during the task on students' oral production complexity and accuracy has largely been evidenced in the literature (Ahmadian, 2012a, 2012b; Ahmadian \& Tavakoli, 2011; Ahmadian, Tavakoli, \& Dastjerdi, 2015; Atai \& Nasiri, 2017; Ellis, 2009; Yuan \& Ellis, 2003). Yuan and Ellis (2003), for instance, explored the impacts on Chinese EFL students' CAF of pre-task and on-line planning conditions through an oral picture-based narrative task. They observed significant improvements in students' oral production complexity and accuracy as a result of both planning conditions. Also, the researchers observed that students' fluency in pre-task planning groups were significantly higher than those in on-line planning groups. 
Ahmadian and Tavakoli (2011) investigated the impacts of both unpressured online task planning and task repetition simultaneously on Iranian EFL learners' oral production CAF. They found that learners' oral production was significantly more complex and accurate in unpressured on-line task planning group compared to pressured one; however, pressured on-line planners outperformed careful on-line planners in terms of their oral production fluency. In another study, Ahmadian (2012a) sought to explore the impacts of guided careful on-line planning on Iranian EFL learners' English articles use CAF. He observed that students produced significantly more accurate English articles under guided careful on-line planning condition. Also, he found that the global complexity of learners' oral production was positively improved under guided careful on-line planning. As for fluency, the findings of the study pointed to an adverse effect of guided and unguided careful on-line planning.

Along the same vein, Ahmadian, Tavakoli, and Dastjerdi (2015) used a combination of a task design feature (i.e. storyline structure of the task) and an implementation procedure (i.e. careful on-line planning) to probe 60 Iranian intermediate EFL learners' oral production CAF. They observed that learners obtained high CAF scores for the structured task under careful on-line planning condition. On the other hand, learners' oral production CAF scores were quite low for the unstructured task under the pressured on-line planning condition. Recently, Atai and Nasiri (2017) examined the impacts of four task planning conditions (i.e. strategic planning, on-line planning, joint planning, and no planning) on Iranian EFL learners' oral production CAF. They made use of two narrative tasks: one simple task containing a series of pictures with a clear storyline and one complex task containing a series of pictures without a clear storyline. They observed significant improvements for accuracy under on-line planning condition in both tasks. As for the impacts of task design feature, the results of the study indicated that learners' oral accuracy and fluency and their oral complexity and accuracy significantly improved under the structured task (i.e. simple task) and the unstructured task (i.e. complex task) respectively.

In a similar study, Baleghizadeh and Nasrollahi Shahri (2017) sought to compare the effect of strategic planning, rehearsal, and on-line task planning conditions on Iranian EFL learners' oral production CAF. The learners were at two levels of proficiency (i.e. low and intermediate levels). The researchers observed that both rehearsal and strategic planning conditions led to significantly more fluent language. As for accuracy and complexity, however, the three planning conditions did not lead to any significant difference. Notwithstanding, the researchers found that there is an interaction effect between learners' proficiency level and planning condition regarding their oral production complexity; that is to say, intermediate- and lower-level participants seemed to perform their most complex performances under rehearsal and strategic planning conditions respectively.

On the whole, the review of the literature above reveals that on-line task planning leads to a more accurate and complex oral language production. What is missing in the literature is a study of the impacts of on-line task planning condition in a testing 
context ( $\mathrm{Li}$, Chen, \& Sun, 2015). Therefore, the present study seeks to explore the contribution of on-line task planning to the testing context. In so doing, the present study focused on examining the effects that the removal of time pressure on task performance in classroom and testing contexts could have on students' oral production. The following are the principal questions that guided the present study:

- Is there any significant difference between pressured vs. unpressured on-line task planning on Iranian L2 students' oral performance in the classroom context?

- Is there any significant difference between pressured vs. unpressured on-line task planning on Iranian L2 students' oral performance in the testing context?

\section{Method}

\subsection{Participants}

To answer the research questions above, a single-factor within-participants design was adopted. It entailed two levels of on-line task planning conditionspressured and unpressured. The participants consisted of 14 intermediate EFL female students from a private language institute in Tehran, Iran. The principal reason for selecting all-female students for the present study was the language institute's policy to run segregated classes, which discouraged the researchers from opting for a coed class. The students' ages ranged from 14 to 23. The students all paid tuition and attended the classes regularly. As for their language proficiency, the participants were considered intermediate, which was demonstrated by the results of the achievement test they had taken at the end of the previous semester at the language institute.

\subsection{Instruments}

Following previous studies on on-line task planning (e.g., Ahmadian 2012a, 2012b; Ahmadian \& Tavakoli, 2011; Ahmadian, Tavakoli, \& Dastjerdi, 2015; Yuan \& Ellis, 2003), on-line task planning is operationalized at two levels in this study: (a) getting students to perform the task right away; and (b) providing students with unlimited time for task completion. The first level of the operational definition above is believed to discourage students from engaging in pre-task planning. The latter level is assumed to provide students with enough time to conceptualize, formulate, and monitor their oral production.

As for the tasks utilized in the present study, they were chosen from part 2 of speaking section of Cambridge Practice Tests for IELTS (1996-2017), where a task card is given to the candidate and he/she is asked to talk about the particular topic in the card for 1-2 minutes after one-minute preparation time. The researchers asked two $\mathrm{PhD}$ graduates in Teaching English as a Foreign Language (TEFL) to check the content validity of the tasks.

The rationale for opting for part 2 of IELTS speaking section was its inherent storyline structure. According to Tavakoli and Skehan (2005, p. 246), a task with "a 
clear time line, a script, a story with a conventional beginning, middle and end, and an appeal to what is familiar and organised in the speaker's mind" is believed to entail storyline structure. It has been empirically shown that a tightly structured storyline has significant impacts on learners' oral and written production CAF, and, therefore, a suitable format for task planning research (Tavakoli \& Skehan, 2005).

All oral task performances were recorded, transcribed, and subjected to scoring procedure in terms of speaking proficiency components, namely fluency and coherence (FC), lexical resource (LR), grammatical range and accuracy (GRA), and pronunciation, which were defined by IELTS speaking band descriptors. It is noteworthy that the researchers did not consider pronunciation for the present study. The scores ranged from a score of 0 to 9 . The three components used in the present study were defined as follows:

- Fluency and coherence (FC): the ability to speak coherently and steadily with only rare repetition or self-correction.

- Lexical resource (LR): the ability to use a wide vocabulary resource, including idiomatic language, readily and flexibly to convey meaning in all topics.

- Grammatical range and accuracy (GRA): the ability to utilize a variety of structures flexibly and appropriately with only very occasional grammatical mistakes.

\title{
2.3. Data Collection Procedure and Analysis
}

The present study pursued two basic aims: (a) to explore the overall effectiveness of pressured vs. unpressured on-line task planning on Iranian L2 students' oral performance in the classroom context, and (b) to explore the overall effectiveness of pressured vs. unpressured on-line task planning on Iranian L2 students' oral performance in the testing context. To achieve these aims and to collect relevant data, the students set for an IELTS Speaking Test- Part 2 in their classrooms prior to their final exam, where they were given two task cards each. The students were supposed to commence speaking on the particular topic of one of the task cards within two minutes and that of the other task card without any time pressure. They were also discouraged from any planning prior to their speech. A sample task card is given below, which is adopted form Cambridge Practice Tests for IELTS (1996-2017).

\author{
Describe a game or sport you enjoy playing \\ You should say: \\ What kind of game or sport it is \\ Who you play it with \\ Where you play it \\ And explain why you enjoy playing it
}


At the conclusion of the instructional period, the students were given two parallel task cards, i.e., IELTS Speaking Test- Part 2, with and without any time pressure for their completion in fulfilment of the requirement for promotion for the next instructional period. It is noteworthy that the order of the task conditions (e.g., pressured vs. unpressured) were counterbalanced to avoid any potential negative impacts of the order of tasks on results (Mackey \& Gass, 2005). Both classroom and testing context task cards were administered by the same teacher. The students' performances in both contexts were recorded using a wireless MP3 audio recorder, transcribed carefully, and subsequently scored based on FC, LR, and GRA indices explained above.

To determine the effectiveness of pressured as well as unpressured on-line task planning conditions, the students were given task cards in their classroom and at the end of the semester in the testing context. The data were then entered into SPSS (version 20) and paired-samples $t$-test was run to find significant effects of the pressured and unpressured on-line task planning conditions in two contexts. To assess the inter-rater reliability of the scoring procedure, a PhD student was asked to score 50 percent of the data, which yielded a correlation coefficient of .82 indicating the reliability of the scoring procedure.

\section{Results}

The following section addresses the research questions posed above and reports the findings of the study. First, the study aimed to investigate the impacts of pressured vs. unpressured on-line task planning on Iranian intermediate L2 students' oral performance in the classroom context. Tables 1 and 2 below present the descriptive results of pressured vs. unpressured on-line task planning in the classroom.

Table 1. Descriptive results of pressured on-line planning in the classroom

\begin{tabular}{llll}
\hline Paired Samples Statistics & & & \\
\hline & $\mathrm{N}$ & Mean & Std. Deviation \\
\hline LR & 14 & 5.3 & 0.21 \\
\hline GRA & 14 & 5.1 & 0.14 \\
\hline FC & 14 & 5.8 & 0.16 \\
\hline
\end{tabular}

Table 2. Descriptive results of unpressured on-line planning in the classroom

\begin{tabular}{llll}
\hline Paired Samples Statistics & & & \\
\hline & $\mathrm{N}$ & Mean & Std. Deviation \\
\hline LR & 14 & 5.1 & 0.12 \\
\hline GRA & 14 & 5.9 & 0.22 \\
\hline FC & 14 & 5.7 & 0.15 \\
\hline
\end{tabular}

Tables above point to a considerable difference between the means of the GRA under the two planning conditions in the classroom context. To answer the first 
research question of the study in statistical terms, a paired-samples $t$-test was run. The results of the analysis suggest that the difference between the means of the GRA under the two planning conditions is significant, $t(13)=-25.438, p=.000$ (two-tailed). However, no statistically significant difference between pressured and unpressured on-line planning conditions in terms of LR, $t(13)=10.333, p=.236$ (two-tailed), and of FC, $t(13)=5.667, p=.236$ (two-tailed) was observed in the classroom context.

Second, the study sought to examine the impacts of pressured vs. unpressured online task planning on Iranian intermediate L2 students' oral performance in the testing context. Tables 3 and 4 below present the descriptive results of pressured vs. unpressured on-line planning in the testing context.

Table 3. Descriptive results of pressured on-line planning in the testing context

\begin{tabular}{llll}
\hline Paired Samples Statistics & & & \\
\hline & $\mathrm{N}$ & Mean & Std. Deviation \\
\hline LR & 14 & 5.1 & 0.14 \\
\hline GRA & 14 & 5.2 & 0.26 \\
\hline FC & 14 & 5.6 & 0.17
\end{tabular}

Table 4. Descriptive results of unpressured on-line planning in the testing context

\begin{tabular}{llll}
\hline Paired Samples Statistics & & & \\
\hline & $\mathrm{N}$ & Mean & Std. Deviation \\
\hline LR & 14 & 5.0 & 0.18 \\
\hline GRA & 14 & 5.8 & 0.26 \\
\hline FC & 14 & 5.6 & 0.14 \\
\hline
\end{tabular}

As it is demonstrated in the tables above, there is a large difference between the means of the GRA under pressured and unpressured on-line planning conditions in the testing context. In other words, GRA of students' oral performance seems to have increased as a result of the removal of the time pressure. Statistically speaking, the results of the paired-samples $t$-test point to a significant difference between the means of pressured and unpressured on-line planning in terms of GRA, $t$ (13) = $19.079, p=.000$ (two-tailed). However, there was no statistically significant difference between the means of pressured and unpressured on-line planning in the testing context in terms of LR, $t(13)=9.539, p=.339$ (two-tailed), and of FC, $t(13)=-1.000, p$ $=.336$ (two-tailed).

\section{Discussion \& Conclusions}

The present study initially sought to investigate the impacts of pressured vs. unpressured on-line task planning on L2 students' oral performance in the classroom context. The findings of the study suggest that students' oral production was significantly more accurate in unpressured on-line task planning condition compared 
to pressured on-line task planning condition. However, the findings of the data analyses suggest no significant difference between pressured and unpressured on-line planning conditions in terms of students' oral production LR and FC.

These findings corroborate those of Ahmadian (2012a, 2012b), Ahmadian and Tavakoli (2011), Ahmadian, Tavakoli, and Dastjerdi (2015), Atai and Nasiri (2017), Ellis (2009), Li and Fu (2016), and Yuan and Ellis (2003) in that unpressured on-line planners are more accurate language users than pressured on-line planners who are usually more fluent language users. For instance, Yuan and Ellis (2003), exploring the impacts of pre-task and on-line planning conditions on students' CAF, reasoned that when time pressured is removed, participants get the opportunity to draw on their syntactic repertoire and, thereby, improve their accuracy.

$\mathrm{Li}$ and $\mathrm{Fu}$ (2016), exploring the impacts of pre-task planning (i.e. strategic planning) and unpressured online planning on 29 Chinese L2 learners' oral production $\mathrm{CAF}$, found that learners' oral production accuracy and syntactic complexity improved under unpressured on-line task planning. The authors argued that strategic and unpressured on-line task planning conditions favor different processing stages, with the former being responsible for generating the conceptual content of speech (i.e. conceptualizer) and the latter being responsible for drawing upon mental lexicon to encode the content (i.e. formulator). Ahmadian and Tavakoli (2011), observing the positive impacts of unpressured on-line planning on Iranian EFL learners' oral production accuracy, concluded that as learners are given more time for task completion, they carefully attend to their rule-based system and fall short of the required attentional resources to be able to process meaning appropriately, resulting in dysfluency.

The second principal objective of the present study was to examine the effectiveness of pressured vs. unpressured on-line task planning on L2 students' oral performance in the testing context. It was found that pressured on-line task planning in the testing context led students to produce fluent and coherent language compared to other indices. It was also found that although the removal of time pressure for test task performance seems to pave the way to students to speak at length and take risks to use new and complex lexical items in their responses, when the time pressure for task completion was removed, students produced more accurate language besides being fluent but lexically simple language.

The findings of the second research question of the study may suggest that as students were cognizant of the fact that they were being assessed, they used simpler lexical items and did not attempt to try out more advanced lexical items. In other words, there seems to be a trade-off (Skehan, 1996) between students' GRA and FC, and their LR in the testing context. According to Skehan (1996), since students have limited processing capacity, they have to inevitably devote their focal attention to just one area of oral performance (i.e., GRA) at the cost of others.

The present study interestingly found that students' FC was quite high under both pressured and unpressured on-line planning conditions. As put by Ahmadian et al., (2015), when "a task implies a relatively clear timeline and macrostructure, 
performers will have more processing resources available to devote to focusing and refocusing attention in real time and linking words and expressions to their meanings and, hence, producing more fluent language" (p. 52). In fact, the storyline structure of part 2 of IELTS speaking section may have resulted in more fluent language production under both pressured and unpressured on-line planning conditions (Tavakoli \& Skehan, 2005).

On the whole, this study suggests that the impacts of on-line task planning in a testing context may be somewhat different from those reported for laboratory or classroom contexts. One reason may be that when students perceive that they are being assessed (Ellis, 2009), they may direct their attention to the grammatical resource and accuracy at the expense of FC and LR. This, in effect, suggests that the 'psychological context' of tasks in the testing context constitutes an important dimension that needs to be taken into account in planning studies. It can be argued that as the time pressure on students on speaking tests is reduced, the opportunity for focus on form (FonF) on the part of students increases. Long (1991) defined FonF as an approach toward teaching which "overtly draw[s] learners' attention to linguistic elements as they arise incidentally in lessons whose overriding focus is on meaning or communication" (pp. 45-46). Therefore, it may be contended that unpressured on-line task planning provides ample time for the controlled processing which is requisite for monitoring; therefore, accuracy is increased.

The findings of the present study have important implications for language teachers and testers who are often striving to foster advanced language use and greater willingness to take risks in their speaking tests in their students. As a result of their limited cognitive capacity (Skehan, 1998; VanPatten, 1990, 2002), students seem to experience difficulty in attending to GRA and FC, on the one hand, and LR, on the other, at the same time in the speaking tests. By becoming cognizant of the demands of testing contexts on students' oral production, language teachers and testers can design appropriate in-class task sequences which would cater for opportunities to attend to GRA and FC as well as LR during task performance.

Notwithstanding the conclusions pointed to here regarding the impacts of pressured vs. unpressured on-line task planning conditions on Iranian EFL learners' oral production, further research is required for the results of this piece of research to be generalized. An apparent limitation on the generalizability of the present research study was the small number of participants. The data for the present study was derived from a sample of 14 all-female EFL intermediate language students. It is obvious that more transparent results would have been obtained with more students. Also, another limitation of the present study was that only one intact class was available for the data collection. In other words, there was limited number of intermediate classes in the site for data collection in the study. It can be reasoned that the inclusion of more groups would contribute to the significance of the findings of the present study. Furthermore, due to institutes' policy to run segregated classes, the researcher could not opt for coed classes, i.e. both male and female learners, to be included in the present study and only female learners were participated in the study. As a result, the findings are limited to female learners. Still, another limitation of this 
study concerns the learners' level of proficiency and age. The participants of this study were all-female EFL learners with different L1 backgrounds, in intermediate proficiency level within an age range of 14 and 23 years. A further limitation of the present study could be related to the administration of task cards in both classroom and testing contexts by the same teacher, which could possibly lead to subjective evaluation of the students' performance at the conclusion of instructional period, i.e., testing context. Therefore, the findings should be interpreted cautiously in generalizing the results to other proficiency levels, age groups, or contexts and language settings (ESL settings). The current study calls for further investigations in this field to explore the impacts of on-line task planning on EFL students' oral production among different proficiency levels, with different age ranges, or in other contexts which might result in different findings from the ones reported in this study.

\section{References}

Ahmadian, M.J. (2012a). The effects of guided careful online planning on complexity, accuracy and fluency in intermediate EFL learners' oral production: The case of English articles. Language Teaching Research, 16(1), 129-149.

Ahmadian, M.J. (2012b). The relationship between working memory capacity and L2 oral performance under task-based careful online planning condition. TESOL Quarterly, 46(1), $165-175$.

Ahmadian, M.J. (Ed.). (2016). Task-based language teaching. The Language Learning Journal, 44(4), 377-380.

Ahmadian, M.J., \& Tavakoli, M. (2011). The effects of simultaneous use of careful online planning and task repetition on accuracy, complexity, and fluency in EFL learners' oral production. Language Teaching Research, 15(1), 35-59.

Ahmadian, M.J., Tavakoli, M., \& Dastjerdi, H.V. (2015). The combined effects of online planning and task structure on complexity, accuracy, and fluency of L2 speech. Language Learning Journal, 43(1), 41-56.

Ahmadian, M.J., \& García Mayo, M.P. (Eds.) (2017). Recent perspectives on task-based language learning and teaching. Boston/Berlin: De Gruyter Mouton.

Atai, M.R., \& Nasiri, M. (2017). An investigation into the effects of joint planning on complexity, accuracy, and fluency across task complexity. Journal of English Language Teaching and Learning, 20, 49-74.

Baleghizadeh, B., \& Nasrollahi Shahri, M.N. (2017). The effect of online planning, strategic planning and rehearsal across two proficiency levels. The Language Learning Journal, 45(2), 171-184.

Ellis, R. (2005). Planning and task-based performance: Theory and research. In Ellis, R. (Ed.), Planning and Task Performance in a Second Language (pp. 3-34). John Benjamins Publishing Co: Philadelphia, PA.

Ellis, R. (2009). The differential effects of three types of task planning on the fluency, complexity, and accuracy in L2 oral production. Applied Linguistics, 30(4), 474-509.

Foster, P., \& Skehan, P. (1996). The influence of planning and task type on second language performance. Studies in Second Language Acquisition, 18, 299-323.

Foster, P., \& Skehan, P. (1999). The influence of source of planning and focus of planning on task-based performance. Language Teaching Research, 3(3), 215-247.

Gass, S. (2003). Input and interaction. In C. Doughty \& M. Long. (Eds.), Handbook of Second Language Acquisition (pp. 224-255). Blackwell Publishers: Oxford.

Keyvanfar, A., \& Modarresi, M. (2009). The impact of task-based activities on the reading skill of Iranian EFL young learners at the beginner level. The Journal of Applied Linguistics, 2(1), 81-102. 
Levelt, W.J.M. (1989). Speaking: From intention to articulation. Cambridge: The MIT Press.

Levelt, W.J.M., Roelofs, A., \& Meyer, A.S. (1999). A theory of lexical access in speech production. Behavioral and Brain Sciences, 22, 1-75.

Li, L., Chen, J., \& Sun, L. (2015). The effects of different lengths of pretask planning time on L2 learners' oral test performance. TESOL Quarterly, 49(1), 38-66.

Li, S., \& Fu, M. (2016). Strategic and unpressured within-task planning and their associations with working memory. Language Teaching Research, 22(2), 230-253.

Littlewood, W. (2004). The task-based approach: some questions and suggestions. ELT Journal, 58, 319-326.

Long, M. (1991). Focus on form: A design feature in language teaching methodology. In K. DeBot, R. Ginsberg, \& C. Kramsch (Eds.), Foreign Language Research in Crosscultural Perspective (pp. 39-52). Amsterdam: John Benjamins.

Long, M. (2014). Second language acquisition and task-based language teaching. Malden, MA: Wiley-Blackwell.

Mackey, A., \& Gass, S. (2005). Second language research: Methodology and design. Mahwah, NJ: Lawrence Erlbaum Associates.

Mackey, A., \& Silver, R.E. (2005). Interactional tasks and English L2 learning by immigrant children in Singapore. System, 33, 239-260.

Markee, N., \& Kunitz, S. (2013). Doing planning and task performance in second language acquisition: An ethnomethodological respecification. Language Learning, 63(4), 629-664.

Mystkowska-Wiertelak, A. (2011). Task repetition as a way of enhancing oral communication in a foreign language. In M. Pawlak, E. Waniek-Klimczak, \& J. Majer (Eds.), Speaking and Instructed Foreign Language Acquisition (pp. 245-257). Bristol, UK: Multilingual Matters.

Ortega, L. (1999). Planning and focus on form in L2 oral performance. Studies in Second Language Acquisition, 21, 109-148.

Saeedi, M. (2013). The influence of strategic planning and storyline complexity on EFL learners' narrative retellings. The Journal of Language Teaching and Learning, 3(1), 20-36.

Skehan, P. (1996). A framework for the implementation of task-based instruction. Applied Linguistics, 17, 38-62.

Skehan, P. (1998). A Cognitive Approach to Language Learning. Oxford University Press: Oxford.

Skehan, P. (2011). Researching tasks: Performance, assessment and pedagogy. Shanghai: Shanghai Foreign Language Education Press.

Skehan, P., \& Foster, P. (1997). Task type and task processing conditions as influences on foreign language performance. Language Teaching Research, 1, 185-211.

Skehan, P., \& Foster, P. (1999). The influence of task structure and processing conditions on narrative retellings. Language Learning, 49(1), 93-120.

Tavakoli, P., \& Skehan, P. (2005). Strategic planning, task structure, and performance testing. In Ellis, R. (Ed.), Planning and Task Performance in a Second Language (pp. 239-273). John Benjamin: Amsterdam.

VanPatten, B. (1990). Attending to content and form in the input: An experiment in consciousness. Studies in Second Language Acquisition, 12(3), 287-301.

VanPatten, B. (2002). Processing instruction: An update. Language Learning, 52(4), 755-803.

Yuan, F., \& Ellis, R. (2003). The effects of pre-task planning and on-line planning on fluency, complexity and accuracy in L2 monologic oral production. Applied Linguistics, 24, 1-27.

\section{Copyrights}

Copyright for this article is retained by the author(s), with first publication rights granted to the Journal.

This is an open-access article distributed under the terms and conditions of the Creative Commons Attribution license (CC BY-NC-ND) (http://creativecommons.org/licenses/by-nc-nd/4.0/). 